\title{
Epistemologia de Certeau e sua Contribuição para os Estudos Baseados em Prática em Organizações
}

Certeau's Epistemology and its Contribution to Practice-Based Studies in Organizations

\author{
Rafael Carvalho Machado' \\ Franciely Chropacz ${ }^{2}$ \\ Yara Lúcia Mazziotti Bulgacov ${ }^{3}$
}

\begin{abstract}
Resumo
O enfoque deste ensaio teórico é apresentar contribuições para possibilidades de pesquisa, sob a perspectiva epistemológica apresentada na obra A Invenção do Cotidiano, de Michel de Certeau, para os estudos organizacionais, especialmente para os estudos baseados em prática. A compreensão de fundamentos ontoepistemológicos associados à leitura retrospectiva dessa obra permitiu estabelecer uma agenda de pesquisa para os estudos baseados em práticas na perspectiva certeauniana. Escolheu-se essa obra porque nela o filósofo destina o seu olhar para as práticas cotidianas, o que o coloca entre os teóricos da "virada da prática". Nela, as ocorrências diárias revelam como a sociedade recebe e consome aquilo que lhe é dado. A contribuição de Certeau para a compreensão do processo de mudança organizacional, em especial nos campos de aprendizagem organizacional e cultura, revelam a importância das micro-ocorrências do cotidiano e como sua perspectiva atribui agência a atores organizacionais a quem a literatura tradicional só atribui papel de reprodução. Ao identificar algumas contribuições e possibilidades da perspectiva do filósofo francês no campo dos estudos organizacionais, este ensaio propõe suas aplicações em estudos de mudança organizacional e organizações não tradicionais, além de conceitos sensibilizadores para a compreensão da lógica da prática social.
\end{abstract}

Palavras-chave: Certeau. epistemologia. práticas. cotidiano. organizações.

\begin{abstract}
The focus of this theoretical essay is to present contributions to research possibilities, from the epistemological perspective presented in Michel de Certeau's work The Invention of Everyday Life, for organizational studies, especially for the ones based on practice. The understanding of onto epistemological foundations associated with the retrospective reading of this work allowed establishing a research agenda for studies based on practice in the Certeau's perspective. This work was chosen because, on it, the philosopher focuses his eyes on every day practices, which places him among the theorists of the turning point of practice. On it, daily occurrences reveal how society receives and consumes what is given to it. Certeau's contribution to understanding the process of organizational change, especially in the fields of organizational learning and culture, reveals the importance of everyday micro-occurrences and how his perspective attributes agency to organizational actors to whom traditional literature only assigns the role of reproduction. By identifying some contributions and possibilities from the perspective of the French philosopher in the field of organizational studies, this essay proposes its applications in studies of organizational change and non-traditional organizations, as well as sensitizing concepts for understanding the logic of social practice.
\end{abstract}

Keywords: Certeau. epistemology. practices. daily. organizations.

Doutorando em Administração (Universidade Positivo) na linha de estudos organizacionais, com foco em aprendizagem e mudança organizacional Mestre em administração (Universidade Positivo, 2017) com foco em inovação e estratégia. Graduado em Administração Pública (EAESP-FGV, 2004).

Mestre em Administração pela Universidade Positivo (2018). Pós-graduada em Auditoria e Perícia Contábil (2017), Direito Constitucional (2014), Direito Público (2012), MBA em Gestão Pública (2008) e Direito Tributário (2007). Bacharel em Direito pela Universidade Tuiuti do Paraná (2002) é Analista Fiscal da prefeitura de Pinhais, desde abril de 2004.

9 Professora Sênior do PPPGADM da Universidade Federal do Paraná. Doutora em Educação pela UNESP; Mestre em Psicologia pela PUC-SP, Graduada em Psicologia pela UEL. Participa, junto ao CNPq, Grupo de Pesquisa: Organizações e Subjetividade, desenvolvendo pesquisas com base epistemológica interpretativa aproximando categorias teóricas da psicologia social sócio-histórica, psicologia comunitaria junto ao campo dos estudos organizacionais. 


\section{Introdução}

Previsões científicas, embora baseadas em métodos científicos bem estabelecidos e comprovados, apresentam pouca capacidade de prenunciar o que ocorre na vida cotidiana. Embora essa incapacidade preditiva possa ser considerada resultado de um problema de transferência de conhecimento ou de imprecisão metodológica (SANDBERG, TSOUKAS, 2011), há uma corrente de pensamento que discute o alcance epistemológico das abstrações da racionalidade científica, formada por pesquisadores que, direta ou indiretamente, preocupam-se com a lacuna entre teoria e prática, levando a incapacidade das teorias de gestão para subsidiar o gestor. Nesse sentido, a virada da prática influenciou uma corrente de pesquisadores na busca por fundamentos ontoepistemológicos que permitam a aproximação com a vida cotidiana (NICOLINI, 2012), em oposição ao pensamento científico tradicional. Os teóricos da prática têm forte influência da "mudança interpretativa ou cultural na teoria social" (RECKWITZ, 2002, p. 244) e colocam em primeiro plano "situações concretas de vida nas quais os atores realizam uma prática comum e, assim, criam e mantêm ordem social" (BUEGER; GADINGER, 2015, p. 7). O interesse particular é no "mundo da vida", no qual as atividades reais e as situações concretas desempenhadas pelos indivíduos têm preponderância sobre intenções e motivações. Esse caminho seria uma alternativa na compreensão de "o significado científico filosófico e social da atividade humana; a natureza da subjetividade, incorporação, racionalidade, significado e normatividade; o caráter da linguagem, da ciência e do poder; e a organização, reprodução e transformação da vida social” (SCHATZKI; CETINA; SAVIGNY, 2005, p. 10).

A escolha da obra de Certeau para leitura, análise e reflexão deu-se, em primeiro lugar, pelo nosso entendimento de seu pertencimento à corrente teórica da virada da prática. Também foi importante para nossa escolha a crescente utilização da perspectiva certeauniana nos estudos organizacionais. De fato, a obra mais utilizada como base teórica para estudos empíricos e reflexivos é A Invenção do Cotidiano, de acordo com a análise bibliométrica em língua inglesa realizada por Faria e Leite-da-Silva (2017), que percebeu que, embora haja certa estabilidade no número de artigos publicados que mencionam a teoria certeauniana, o número de periódicos em que textos com essa base epistemológica são publicados aumentou nos últimos anos, demonstrando a popularização dessa perspectiva nos estudos organizacionais. Na pesquisa em organizações desenvolvida no Brasil, uma revisão sistemática realizada por Machado, Fernandes e Silva (2018) demonstra como a teoria certeauniana vem se popularizando. A análise das publicações em português, entre 2008 e 2015, que utilizam sua filosofia como eixo analítico mostra que o número de publicações cresceu sensível e consistentemente nesse período.

$\mathrm{Na}$ referida obra, Certeau possibilita que se olhe para o sujeito comum e dele se apreenda as "maneiras de fazer" que constroem processos organizativos. Naquelas páginas, apresenta-se o "homem ordinário", no sentido de regular, popular, mas que é, ainda, pouco conhecido e, por isso, "folclorizado" (CERTEAU, 2014, p. 38). Ele é, no entanto, um praticante tanto quanto outros agentes sociais. Mesmo que afastado da "cultura erudita", vindo da "história muda", decorrentes das culturas ordinárias, prosaicas, suas experiências particulares caracterizam maneiras de fazer, histórias contadas por quem a constrói cotidianamente.

As organizações fazem parte da vida contemporânea. Sua "presença faz parte da modernidade e sua importância cresce a ponto de assumirmos, hoje, que as sociedades são naturalmente compostas por organizações" (SPINK, 2001, p. 12). Os comportamentos, as práticas, as falas são fragmentos das ações cotidianas de atores inseridos nessas organizações. Portanto, a organização é um todo inteiramente expressivo. Diante disso, o pesquisador que enveredar por esse caminho terá diante de si um lugar onde os processos internos são produtores de sentidos e significados sociais, refletidos no cotidiano coletivo, revelando como o cotidiano é uma fonte de dados para o estudo das ocorrências organizacionais. Um caminho que já se mostra promissor para a compreensão do cotidiano das organizações é o apontado por Certeau.

O cotidiano é o ambiente no qual florescem as ações dos atores. Ele é o atual, o real, não há como se afastar dele porque faz parte do viver de cada pessoa, mas também como elemento integrante das organizações. Por ser uma experiência humana, é autêntico, no sentido de ser criado diariamente e com a participação de todos. O termo cotidiano é um vocábulo usado frequentemente sem que se domine sua definição. É como chamar de normal algo que é comum, mas que não pode ser normal porque não está respaldado em norma instituída pelo devido processo legal. Portanto, quando Certeau fala em "difícil delimitação" (2014, p. 103) é porque sua amplitude deve ser pensada e tratada naquele contexto que se quer transmitir. Faz-se necessário observar o discurso, a ocasião em que ele é estabelecido, para daí traçar os parâmetros que permitem nortear uma espécie de posição a ser adotada.

O objetivo deste artigo é explorar, a partir de A invenção do Cotidiano, possíveis contribuições conceituais do pensamento de Certeau para a compreensão do holístico cotidiano organizacional. Para tanto, o artigo está dividido em cinco partes (a partir desta introdutória): Práticas sociais e cotidiano; Contribuições de Certeau para os estudos organizacionais; Voltando-se para o cotidiano; Entre táticas e estratégias; Relato para compreender o cotidiano, além de Considerações finais. 


\section{Práticas sociais e o cotidiano}

Muitas vezes, o conceito de prática é utilizado de forma confusa, levando a dificuldades na coleta e análise ao se deparar com o cotidiano da prática. A falta de um conceito robusto leva a falhas na interpretação das ações dos atores e à incapacidade de apreender o social no campo. Não se deve confundir o conceito de abordagem das práticas com uma simples observação de eventos, episódios, regras, ou ainda com métodos que buscam proximidade com a realidade (SANTOS; SILVEIRA, 2015), embora se trate de uma abordagem que procura observar o cotidiano dos indivíduos. As diversas abordagens teóricas dos estudos das práticas sociais tratam de forma diferente esse movimento de construção teórica do objeto "prática".

Orlikowski (2015) ajuda-nos a compreender as diferentes abordagens desse objeto. Ela apresenta três formas de analisá-lo. Primeiro, tomando a prática como fenômeno empírico, que orienta o problema da pesquisa. A prática, nessa perspectiva, é um fenômeno que presenciamos no nosso dia a dia, ao qual todos temos acesso. Depois, a prática pode ser tomada como perspectiva: com a proposição de teorizar sobre o cotidiano, revelando os processos de constituição do emaranhado de "práticas" que produzem, reproduzem e transformam a realidade social. Aqui, podemos escolher teorias e conceitos sensibilizadores para iluminar a realidade investigada. Finalmente, Orlikowski (2015) destaca a abordagem filosófica da prática, que é o pressuposto ontológico assumido pelos pesquisadores da prática. Ela parte do princípio que a realidade pode ser concebida pela prática como unidade de análise: é constituída pelo encadeamento de práticas orientadas para objetos, que, em suas configurações, dariam conta da complexidade, da totalidade do cotidiano. A prática é uma unidade de análise complexa e coletiva, constituída por diversos elementos interconectados: os desempenhos, teleoafetividade voltada a um objeto, mente, corpo, artefatos, regras e outras mediações culturais.

Uma referência útil para entender a prática nos é dado por Czarniawska (2015) ao identificá-la como uma "forma coerente e complexa de atividade humana cooperativa socialmente estabelecida" (p.106). Por coerente, podemos entender que a prática esteja sujeita a uma lógica, ainda que diferente daquela da racionalidade própria dos modelos científicos. No mesmo sentido, Reckwitz (2002) afirma que o resultado das práticas sociais costuma ser "relação estável entre agentes e coisas dentro de certas práticas [que] reproduz o social, assim como a relação 'mutuamente' estável entre vários agentes em outras práticas" (p. 253). Essa reprodução seria evidente no dia a dia dos indivíduos através das ações que os atores carregam. Trata-se, portanto, de uma visão de reprodução da ordem social.

Para Spink (2001), reforçando essa lógica, a racionalidade das práticas destaca as organizações como o conjunto de práticas, as ações e as falas dos atores constituindo um todo expressivo diante do qual o pesquisador terá um lugar onde os processos internos são produtores de sentidos e significados sociais, refletidos no cotidiano coletivo, revelando como o cotidiano é uma fonte de dados para o estudo das ocorrências organizacionais. A organização, assim, seria um emaranhado de práticas configurando uma realidade.

Essa lógica tem sido objeto de investigação de numerosos estudiosos da prática (por exemplo, NICOLINI, 2009; TSOUKAS, 2005; CZARNIAWSKA, 2015; BUEGER; GADINGER, 2012; BORDIEU; PASSERON, 1990; SCHATZKI; CETINA; SAVIGNY, 2005). Embora os diversos teóricos da prática concordem que a lógica de ação humana segue uma racionalidade própria - de um homo praticus, em contraste com as metáforas do homo economicus e homo socius - cada um estabelece diferentes elementos constituintes da prática social, assim como estruturas de relacionamento entre elas, sua estabilidade e reprodução (para mais detalhes quanto às diferentes abordagens da prática social, ver NICOLINI, MONTEIRO, 2007). Esse modus operandi, no entanto, não precisa ser estático. As práticas não são apenas regularidades, mas sim "arranjos de pessoas, artefatos e coisas (...) [que] governam tanto os significados das entidades organizadas quanto às ações que trazem providências" (SCHATZKI; CETINA; SAVIGNY, 2005, p. 15-16).

Isso sugere que há espaço no cotidiano dos atores para a transformação das práticas ao passo da transformação dos sentidos, das regras e, de forma geral, da própria prática. A transformação pode ser resultado de transformações de sentidos no tempo (NICOLINI; MONTEIRO, 2017), como por meio do aprendizado da comunidade (WENGER, 2010) ou da ressignificação por meio de um processo interpretativo (BISPO; GODOY, 2012). Dessa forma, o cotidiano para os estudos baseados em práticas sociais é fundamental para a mudança para um paradigma de organização interpretativa (MASCARENHAS, 2002).

\section{Contribuições de Certeau para os estudos organizacionais}

Há um crescente interesse da comunidade científica em estudos baseados em práticas sociais no campo de estudos organizacionais e, sobretudo em temas como estratégia e gestão, têm sido tratados de forma mais heterogênea, entendidos como práticas sociais que acontecem no cotidiano, sem uma tendência a universalizar soluções corretas (para uma análise mais detalhada, ver Machado, Fernandes, Silva, 2018). Áreas como estudos de inovação e sustentabilidade também têm reconhecido cada vez mais a importância de entender a prática dos sujeitos ao invés da criação de modelos abstratos de comportamento (KOHLER et al, 2019), além de estudos de aprendizagem e cultura.

Certeau tem sido especialmente utilizado em pesquisas empíricas em torno de práticas sociais. Nos estudos organizacionais, o estudo baseado em práticas observa minuciosamente uma organização em busca do "fazersentido" compreendido. A unidade de análise então é a própria prática. Olhar para a prática social como unidade 
de análise contribui com o avanço da teoria de organizações, que se tornou demasiadamente abstrata e distante das atividades cotidianas, a qual se propunha originalmente a descrever (BULGACOV, CHAVES, VILELA, VOGT, 2016). A perspectiva de Certeau nos apresenta um método próprio para a compreensão do cotidiano que pode ser aplicado aos estudos de organizações.

O filósofo francês Michel de Certeau propõe uma visão epistemológica centrada na compreensão do processo de consumo cultural do indivíduo comum: processo de apropriação de objetos, rituais, leis e linguagem. Sua obra A Invenção do Cotidiano (CERTEAU, 2014) discute como esse processo acontece e como pode ser investigado. Seu convite é olhar o indivíduo comum no sentido de apreender suas "maneiras de fazer" que constroem os processos organizativos. Sua obra é voltada para "homem ordinário", homem popular, "folclorizado" (CERTEAU, 2014, p. 38), ainda pouco conhecido, entretanto um praticante tanto quanto outros agentes sociais. Mesmo afastado da "cultura erudita", vindo da "história muda", decorrentes das culturas ordinárias, prosaicas, suas experiências particulares caracterizam maneiras de fazer, histórias contadas por quem as constrói cotidianamente.

Esse homem ordinário é o consumidor cultural no momento em que interage com artefatos, faz uso deles conforme a sua necessidade. As "maneiras de fazer" transformam as práticas, alterando o funcionamento sobre aquilo que é imposto pela ordem social dominante. "Essas 'maneiras de fazer' constituem as mil práticas pelas quais usuários se reapropriam do espaço organizado pelas técnicas da produção sociocultural” (CERTEAU, 2014, p. 41), ou seja, os usuários, por meio das diversas práticas, agem (que são as maneiras de fazer) para realizar uma nova configuração (alterar o funcionamento) sobre aquilo que é imposto pela cultura dominante.

Chama atenção que Certeau conceitua o consumo pelo indivíduo comum de apropriação. Apropriação traz a conotação de agência, de um homem ativo que transforma as práticas e altera seu funcionamento. É essa a concepção de indivíduo por trás do termo "invenção" no título da obra. O homem ordinário não apenas reproduz o cotidiano, mas lhe imprime uma assinatura. $\mathrm{O}$ foco da investigação social é um indivíduo que, através de suas experiências, suas maneiras de fazer e suas maneiras de contar, constrói, cotidianamente, os processos organizativos. Em outras palavras, os processos organizativos são, segundo o autor, carregados pelas maneiras de fazer e de contar do homem ordinário: um praticante, um inventor.

Na perspectiva certeauniana, aceitamos o conceito de produção como uma mudança intrínseca da prática. Sem ele, a mudança na prática seria meramente extrínseca ou racional num estágio reflexivo da prática. A lógica das artes de fazer proposta por Certeau (2014) atribui aos praticantes ordinários a criatividade - elemento interno - que Ihes permite adaptar as operações postas de acordo com o cotidiano no qual estão inseridos. Devemos considerar o indivíduo comum como agente, não como dominado, pois "não se deve subjugar a inteligência e a capacidade inventiva do mais fraco" (CERTEAU, 2014, p. 19). É o mais fraco que pratica a arte da ordem e, ao mesmo passo, a burla. Para essa perspectiva, são as artes de fazer que diferenciam aquilo que é produzido pelo "homem ordinário" da ordem social dominante e, por meio dessas artes, sujeitos comuns conseguem tecer histórias próprias de resistência (DURAN, 2012). Dessa forma, Certeau contribui para os estudos organizacionais ao permitir uma compreensão mais aprofundada da capacidade de agência dos indivíduos em comunidades e organizações, daí o interesse de campos ligados à aprendizagem e a inovação.

A experiência é tomada como uma categoria epistemológica: aquilo que se experimenta, nos forma e nos transforma (BONDÍA, 2002). Ao colocar em destaque a experiência cultural e a subjetividade humana como construtora da realidade associativa processual, Certeau se afasta de estudos fundamentados em teorias científicas e abstratas, que não consideram corpos e coisas. A posição antipositivista de Certeau fica clara na medida em que considera os processos de apropriação do indivíduo, ou seja, a dimensão da subjetividade humana para a compreensão da ação. Certeau legitima as maneiras de fazer e de falar do homem ordinário como constituintes da lógica prática.

Os consumidores culturais produzem "trajetórias indeterminadas" (CERTEAU, 2014, p. 91), que são respostas ao sistema imposto e, quando confrontadas com o espaço constituído, parecem não ter sentido ou ação sobre o espaço. Elas, contudo, não apenas constituem e formam a malha simbólica do emaranhado de práticas culturais que Nicolini (2012) chama de "fazer-sentido" compreendido - como vão trabalhando/erodindo com esse sistema, conforme vão tendo acesso a esse terreno. O pesquisador, nessa perspectiva, tem como foco o encadeamento e o sentido cultural das práticas e seu "movimento temporal no espaço", buscando revelar a racionalidade cultural. Busca-se o sentido das ações e não os eventos.

Ao dar voz a sujeitos esquecidos pela história, vários estudos foram desenvolvidos em organizações que não são tradicionais nos estudos organizacionais: feiras, cooperativas, organizações escolares e artísticas foram estudadas com base em conceitos de Certeau. Da mesma forma, atividades profissionais fora do tradicionalmente estudado no campo da administração são objeto de análise: de catadores de material reciclável a caixeiros viajantes (MACHADO, FERNANDES, SILVA, 2018). Dessa forma, abrem-se caminhos para a compreensão de organizações e indivíduos que antes estavam fora do campo de análise dos estudos organizacionais, ampliando o alcance desse campo.

Um dos enigmas das ciências sociais é compreender como os dominados aceitam determinada ordem dominante (PASSERON, 2005). A epistemologia de Certeau contribui para os estudos sociais ao mostrar novas facetas desse enigma ao pensar a relação dominante/dominado além das oposições evidentes. Ainda que, no primeiro momento, as organizações tenham poder sobre as maneiras de fazer ao estabelecer o que os indivíduos devam consumir, os 
estudos organizacionais baseados em prática devem olhar para o "homem ordinário" em sua maneira de consumir a ordem imposta. A organização não se faz somente de instrumentos, mão de obra e resultados. Ela é muito maior que isso. Dessa forma, avança-se para o estudo da linguagem praticada nos ambientes organizacionais, com a expectativa de captar um retrato mais próximo daquilo que ela é. Ao praticante, no processo de consumo, cabe o reemprego daquilo que lhe é dado, procedendo a uma aculturação sobre a própria cultura dominante.

\section{Voltando-se para o cotidiano}

A Invenção do Cotidiano apresenta uma crítica contundente à epistemologia tradicional. A pergunta fundamental dessa obra é "como se cria?". Para responder essa pergunta, Certeau desloca sua atenção daquilo que ele chama de consumo e para o que ele chama de produção. Não no sentido de consumo de bens ou serviços, mas no sentido cultural: o consumo da cultura da sociedade traz consigo um processo de produção, imprevisível e anônimo, "nascido da prática do desvio no uso desses produtos" (CERTEAU, 2014, p. 12). O interesse não está na cultura em si, mas no desvio operado pelos indivíduos cotidianamente. A produção é um processo indissociável do consumo cultural. Existe, assim, liberdade nas práticas cotidianas, num movimento aparentemente aleatório, fundado em microliberdades, microrresistências, micropoderes operados pelos usuários, ilustrado na parábola da catequização de indígenas da América do Sul apresentada pelo filósofo: embora tenham aprendido o Deus dos europeus, esse mesmo Deus fazia sentido dentro da cultura indígena. A obra busca explorar qual a lógica por trás desse movimento. Assim, Certeau destaca que "as práticas do espaço tecem condições determinantes da vida" (CERTEAU, 2014, p. 163). São procedimentos multiformes, resistentes, astuciosos, teimosos, que estão fora da disciplina, mas dentro do campo em que ocorrem, tecendo uma teoria das práticas cotidianas. As práticas são um saber sobre os quais os sujeitos não refletem. É como se fossem locatários e não proprietários das práticas. É um saber que circula entre a inconsciência dos praticantes e a reflexão deles. Há um saber nas práticas e esse saber tem cientificidade para ser transportado do inconsciente para o consciente (CERTEAU, 2014).

Essa imprevisibilidade no cotidiano exige uma concepção epistemológica que dê conta da singularidade e, nesse sentido, a sondagem estatística enfrenta uma grande limitação. Os dados numéricos e suas escalas só têm validade no contexto em que foram coletados e são capazes de representar o produto, mas não o consumo, por isso é necessária a busca por um paradigma epistemológico adequado para estudar o cotidiano.

O fundamento epistemológico de sua teoria é que não há usuário meramente consumidor e, dessa forma, não há dominação completa. Usar um objeto abre espaço para a criação, uma "caça não autorizada" (CERTEAU, 2014, p. 38). As maneiras de fazer tratam de explicitar como os consumidores produzem ao consumir: "a 'fabricação' que se quer detectar é uma produção, uma poética - mas escondida (...) [de] produtos próprios, mas nas maneiras de empregar os produtos impostos por uma ordem" (CERTEAU, 2014, p. 38-39).

A "fabricação" que se quer detectar está, portanto, escondida pelo que é produzido pelo "sistema" que não deixa os consumidores se manifestarem, até porque há uma dispersão/pulverização muito grande, haja vista que os consumidores estão em todos os lugares. Quando se olha pesquisas sobre consumo, vê-se informações estatísticas, mas também operações realizadas pelos usuários. Ao invés de analisar as propagandas na TV, deve-se perguntar o que o consumidor faz com essas imagens. O que se absorve dessas propagandas? O que fazem com isso? Assim, as "astúcias" dos consumidores tornam-se "invisíveis" (CERTEAU, 2014, p. 39), sendo percebidas na forma com que os produtos são usados, que são "maneiras de empregar os produtos impostos por uma ordem econômica dominante" (CERTEAU, 2014, p. 39). Aquilo que é imposto passa a ser usado com outra finalidade, diferente da original. É esse desvio que Certeau chama de cotidiano e sua operação, a maneira de fazer.

A criatividade no emprego dos produtos não é somente de pequenos grupos, mas uma coletividade, uma massa. No entanto essa massa não é homogênea na sua criação, porque o mesmo produto que é ofertado aos diferentes praticantes, que estão em diferentes "situações sociais e relações de força" (CERTEAU, 2014, p. 44), recebe diferentes empregos.

As maneiras de fazer podem ser materializadas pela produção daqueles atores, situações que Certeau diz que são fabricadas por eles $(2014$, p. 38). Essa produção retrata a criatividade daqueles que a realizam. Pode ser que essa criação não seja amplamente conhecida, já que está escondida, contudo seus resultados são percebidos na forma com que as criações são usadas, pelas "maneiras de empregar os produtos impostos por uma ordem econômica dominante" (CERTEAU, 2014, p. 39).

O consumo é, portanto, uma forma astuciosa, dispersa e quase invisível de produção, capaz de transformar a ordem social. Certeau aproxima a lógica na realização da prática, como uma maneira de discutir uma imposição, tornando-a amigável, próxima, praticável à sua maneira em uma organização das artes: a arte de fazer. Artes são atividades que modificam a ordem imposta, reformando a cultura nas "relações conflituais ou competitivas entre mais fortes e mais fracos" (CERTEAU, 2014, p. 81). Cabe ao mais fraco, ou seja, ao homem comum, o desempenho dessas artes.

Certeau faz com que o olhar do cientista seja dirigido para a vida diária e para os pequenos detalhes que formam o cotidiano: "O caminho técnico a percorrer consiste, em primeira aproximação, em reconduzir as práticas e as línguas científicas para seu país de origem, a everyday life, a vida cotidiana" (CERTEAU, 2014, p. 62). Essa nova 
perspectiva de olhar o dia a dia, em que se operam as pequenas resistências - produtos tornados invisíveis - revela produtos organizacionais por vezes desconhecidos.

As "artes de fazer" são, portanto, maneiras de discutir uma imposição, tornando-a amigável, próxima, praticável à sua maneira em uma organização. Conhecendo-se as "artes de fazer" pode-se compreender a sua realização e o porquê da sua ocorrência. Essas marcas individuais indicam a cultura daquela organização, que poderá ressaltar sua singularidade ou um detalhe na sua prática cotidiana.

A mudança paradigmática proposta pelo autor está em considerar o indivíduo comum como agente, não como dominado, pois "não se deve subjugar a inteligência e a capacidade inventiva do mais fraco" (CERTEAU, 2014, p. 19). É o mais fraco que pratica a arte da ordem e, ao mesmo passo, a burla. Para essa perspectiva, são as artes de fazer que diferenciam aquilo que é produzido pelo "homem ordinário" da ordem social dominante e, por meio dessas artes, sujeitos comuns conseguem tecer histórias próprias de resistência (DURAN, 2012). Os olhos do pesquisador do cotidiano devem, portanto, estar voltados para esse homem.

Esse ponto de referência do homem comum é também defendido por Spink (2008, p. 70), quando afirma que os estudos das práticas voltam seu olhar para o corriqueiro, destacando que todos os indivíduos possuem um cotidiano com elementos valorizáveis, que possibilitam uma infinidade de dados informativos de práticas, embora a sociedade prefira destacar o cotidiano de um presidente em detrimento do operário. As práticas são procedimentos que os indivíduos desempenham com a finalidade de realizar as atividades que são necessárias para a execução de um ato, são formadas de "materialidades, socialidades e institucionalidades" (SPINK, 2009, p. 232).

Voltar-se para o que acontece no dia a dia dos sujeitos comuns é um caminho para compreender como as pessoas se comportam dentro de organizações. As perguntas de pesquisa passam de colocar a organização como agente e reconhecê-las como um processo que ocorre a partir do comportamento coletivo. Não se deveria, na perspectiva certeauniana, perguntar qual o efeito que as normas organizacionais causam nos indivíduos, mas sim o que os sujeitos fazem quando se deparam com uma norma: como interpretam, reagem e desenvolvem sua "arte". Convencidos, então, da direção que devemos olhar, a reflexão de Certeau nos dá pistas do que devemos procurar no cotidiano.

\section{Entre táticas e estratégias}

Há dois conceitos fundamentais para a compreensão do cotidiano e da produção operada pelo homem ordinário de Certeau: as táticas e as estratégias. É importante, para a compreensão da epistemologia de Certeau, clarificar esses conceitos, vista a confusão, nos estudos organizacionais, em relação ao termo estratégia no contexto empresarial e as estratégias de produção cultural propostas pela teoria (MACHADO, FERNANDES, SILVA, 2018). Trata-se de dois modos de ação no mundo que se revelam na observação da realidade.

A relação entre táticas e estratégias é, aparentemente, antagônica. As táticas se referem às formas de utilização - as artes de fazer - oportunas, ordinárias e imprevisíveis. As estratégias, de outro lado, são uma espécie "vitória do lugar sobre o tempo [que] permite ao indivíduo gerenciar sua relação com a exterioridade" (CERTEAU, 2014, p. 46). Estratégias não são imprevisíveis, mas sim racionais; não são oportunas, mas sim deliberadas; tampouco são do homem comum, mas sim do homem nobre. No entanto a relação é mais complementar que antagônica: não há tática sem estratégia, assim como não há consumo sem produto (PEREIRA, SARTI, 2010).

Certeau afirma que as estratégias são meios de articulação que condicionam as relações sociais e de dominação de um determinado espaço. Nessa afirmação, espaço é um lugar em que se desenvolve uma prática em uma configuração momentânea de posições, na qual há um dominante que indica uma relação de estabilidade e poder. Essa dominação acontece em um lugar próprio, que deliberadamente sustenta a dominação e controla o espaço. Importante ressaltar que esse conceito de estratégia é alvo de críticas, sobretudo pela possibilidade de emergir dele uma concepção racionalista de poder, o que não é adequado para a compreensão da complexidade do cotidiano proposto por Certeau.

Já as táticas são ações determinadas justamente "pela ausência de um [lugar] próprio. Então nenhuma delimitação de fora the fornece a condição de autonomia. A tática não tem por lugar senão o [espaço] do outro. (...) [ela] é movimento 'dentro do campo de visão do inimigo'" (CERTEAU, 1994, p.94). Portanto, as táticas são pequenos golpes à dominação, dados "em voo", dentro do espaço de controle do dominante. Não há avaliação do ambiente ou deliberação prévia de uma ação: "aproveita as 'ocasiões' e delas depende, sem base para estocar benefícios, aumentar a propriedade e prever saídas" (CERTEAU, 1994, p.95). Táticas não têm um objetivo global a ser atingido pelo dominado, mas transformam a ordem social por meio do consumo e a torna mais "palatável" para os indivíduos comuns. Elas representam a arte de fazer cotidiana do homem ordinário.

A visibilidade das táticas se dá nas ocasiões em que se permite ao usuário "criar" um produto próprio. São elas que constituem a arte de fazer do fraco, a ocasião em que se produz enquanto se consome. A definição de tática elaborada por Certeau (2014) considera que ela é uma ação calculada para o aproveitamento de uma ocasião com a finalidade de ampliar os resultados do seu praticante.

Essas duas lógicas de ação distintas - a estratégia e a tática - são diferentes para o indivíduo que domina e que é dominado, no entanto essas posições são instantâneas. Isso significa que o indivíduo dominante em um 
espaço próprio pode ser o dominado em outro, da mesma forma que a relação de dominante/dominado pode se transformar em determinadas condições.

O próximo dilema a ser tratado na epistemologia proposta por Certeau é como ver essa produção invisível das táticas, que não se acumulam e ocorrem despistadamente. Na investigação social de Certeau, a compreensão dessas lógicas de ação do homem passa pela observação da linguagem. Por meio dela é possível entender regras por trás dos golpes operados contra uma ordem dominante. Não é necessário compreender os eventos que ocorreram, mas sim evidenciar as regras da dominação. As duas lógicas de ação são expressas em duas formas de linguagem igualmente distintas: a oralidade e a escrita. A escrita é investida de um poder estratégico e racional consagrado. Dominante, é dela que emerge a cultura escriturística que enclausura a retórica. Considerando as formas de enfrentamento e criatividade do homem ordinário, outro destaque importante da perspectiva certeauniana é a importância do relato: a importância da narrativa como meio para se reconhecer a racionalidade prática.

\section{Relato para compreender o cotidiano}

É certo então que "a retórica ou ciência das 'maneiras de falar' oferece um aparelho de figuras típicas para a análise das maneiras cotidianas de fazer" (CERTEAU, 2014, p. 47). É com isso que ele substitui o binômio produçãoconsumo por seu equivalente geral: escritura-leitura. Na leitura há espaço para a produção. Não é o autor quem produz, mas sim o leitor. Quem lê transforma as relações existentes no texto.

Na busca pelos golpes cotidianos operados contra a ordem social pelo "homem ordinário", Certeau apresenta mais uma crítica à epistemologia tradicional, agora sobre o novo binômio escritura-leitura. As explicações para o processo de produção estão na maneira de falar, e não na maneira de escrever. A escrita se depara com uma folha em branco a ser preenchida, isolada do indivíduo, um espaço próprio para a produção - uma estratégia. Já a "oralidade se insinua (...) na trama" de uma economia que valoriza o texto escrito e, com isso, "se apresenta a produção de sentido dos artefatos para com os usuários e seu uso no cotidiano" (CERTEAU, 2014, p.202).

O cotidiano, por meio da linguagem, vê na oralidade a autonomia estabelecida em relação aos textos dos quais depende a transformação de relações sociais, daí conclui que é no relato oral que reside o teatro que legitima as ações: "somente uma memória cultural adquirida de ouvido, por tradição oral, permite e enriquece aos poucos as estratégias de interrogação semântica cujas expectativas a decifração de um escrito afina, precisa ou corrige" ( $p$. 240). Na narração do indivíduo que se observa, portanto, o cotidiano; é um ponto de chegada de uma trajetória e a técnica da pesquisa trata de reorganizar o lugar que produziu o discurso.

A fala, para Certeau, é muito mais que o conhecimento da língua, abarcando uma combinação mais ampla para efetuar a comunicação, trabalhando com a apropriação e reapropriação, os quais indicam uma cultura própria atrás dessas ações, revelando um determinado tempo e lugar, formando uma rede de interações. A maneira como Certeau entende a fala permite analisar as práticas realizadas pelos consumidores, porque nenhum fato é simples, nenhuma ação é desprovida de sentido e significado.

Na fala, deve-se analisar as dimensões da lucidez e da falsificação, pois no discurso das palavras há consciência, clareza, uma razão, mas também há palavras modificadas, adulteradas ou, até mesmo, a proibição de dizer (CERTEAU, 2014). A lucidez revela a verdade, o discurso sincero e legítimo dos atores. Por outra volta, as palavras falsificadas são os desvirtuamentos no dizer, bem como as palavras que, ditas, não encontram ressonância naquele lugar. Certeau sustenta que o consumidor pode ser qualificado pelos produtos que adquire, porque há uma forma diversa de utilizá-los, diferente da original (o que impede essa qualificação) e, por isso, "deve-se analisar o uso por si mesmo" (CERTEAU, 2014, p. 90). Assim, no estudo da linguagem, deve-se observar o uso ou o contexto em que foi utilizada.

A compreensão da cultura busca alcançar em verdades narrativas - através de relatos - as regras da sociedade. Certeau lança a pista que situações simuladas, tais como os jogos e as lendas, criam um espaço em que o homem ordinário pode mostrar sua capacidade de indisciplina frente a uma ordem social. Jogos e lendas não são mais que relatos elaborados a partir de situações fictícias que representam o imaginário e utópico, num espaço que foge das regras do mundo real da sociedade e, assim, "protege as armas do fraco contra a realidade da ordem estabelecida" (CERTEAU, 2014, p.80).

Essa perspectiva coloca a ciência social numa posição diferente da tradicional, usando como material de trabalho a sucata da ciência tradicional, pois "tratar assim as táticas cotidianas seria praticar uma arte 'ordinária', achar-se na situação comum e fazer da escritura uma maneira de fazer sucata" (CERTEAU, 2014, p.85). A cultura se encontra, portanto, não no que as pessoas fazem, mas sim naquilo que contam. A retórica é importante e nela Certeau vê a chave para compreensão do cotidiano.

Assim, o relato do homem ordinário assume o papel de ferramenta epistemológica na perspectiva de Certeau. Ele é a linguagem das táticas operadas pelo homem comum em seu processo de consumo e nele se encontram as microliberdades, as microrresistências, os micropoderes do cotidiano. É através dele se desvenda a lógica que transforma a prática social. Sua maneira de olhar para esses processos, entendendo que são uma forma de criação - e não apenas uma forma 
passiva de consumo -, sustenta uma concepção não bourdieusiana de prática social, uma vez que ela se transforma no tempo como resultado do consumo do homem ordinário. Justamente essa transformação é a invenção do cotidiano.

\section{Considerações Finais}

No contexto da busca por alternativas epistemológicas que deem conta de explicar as práticas sociais nas organizações, a obra A Invenção do Cotidiano, de Certeau, dá atenção a aspectos muito negligenciados pela racionalidade científica tradicional: o cotidiano, o homem ordinário, as microliberdades e micropoderes do processo de consumo. Há espaço, portanto, para a ressignificação promovida pelos indivíduos, pelos praticantes e, para Certeau, essa ressignificação acontece no cotidiano.

O relato, a proposta de enfatizar as narrativas dos praticantes como meio de compreensão da racionalidade prática, complementa a caracterização da base epistemológica proposta por Certeau na perspectiva da racionalidade prática em oposição à racionalidade cientifica (SANDEBERG; TSOUKAS, 2011). De outro modo, a partir do modo de produção narrativo em oposição ao modo cientifico (BRUNER, 1997).

Ao se perguntar "como se cria?", Certeau inicia uma linha de pensamento que vê no consumo cultural a possibilidade de criação. A inseparabilidade do binômio produçãocriação exige uma lógica que explique o aparente movimento aleatório do consumo dos indivíduos. Para compreender essa lógica, Certeau lançou mão da observação do cotidiano do homem ordinário. Este - dominado por uma ordem social - transforma os significados nas ocasiões que lhe é dada a liberdade e, golpe por golpe, transforma o seu cotidiano e escreve sua história.

O termo escrever aqui não é acidental: a epistemologia proposta por Certeau é textualista e vê na linguagem o caminho para investigar o cotidiano. A economia escriturística moderna privilegia a escrita à oralidade. A escrita, contudo, não traz consigo a espontaneidade da tática, mas a racionalidade da estratégia. Certeau propõe, então, a utilização de relatos como método para explicar o cotidiano. De fato, os estudos organizacionais que utilizam Certeau como sua base teórica privilegiam a observação, a coleta de narrativas e entrevistas como estratégia de coleta de dados, em detrimento da análise documental, por exemplo.

Até aqui, Certeau contribui com estudos de organizações não tradicionais e também de indivíduos que são esquecidos por epistemologias tradicionais de estudo social. Porém organizações são mais que metas, mão de obra e ativos: são formadas de várias práticas que não apenas sistematizam aquilo que são, mas também permitem que uma organização se diferencie da outra. É o que os indivíduos fazem no cotidiano organizacional que estrutura sua cultura. Assim, Certeau pode ainda ampliar a capacidade de visão dos estudos organizacionais, ao apresentar um caminho para a compreensão de uma lógica de ação dos homens ordinários que se organizam, que permaneceu invisível até aqui. Sua contribuição, contudo, pode ir além do tipo de organização e indivíduo pesquisado, mas repensar a própria concepção da organização ao buscar superar a reificação do objeto/organização e demonstrar as mediações culturais que constituem os processos organizativos em movimento.

Ainda que a perspectiva certeauniana não seja propriamente uma novidade para os estudos organizacionais, a reflexão ontoepistemológica da obra analisada contribui, a nosso ver, para revelar a proposta de Certeau como uma alternativa para desvendar o cotidiano, a imprevisibilidade da lógica da prática. São demandas clássicas dos gestores e dos pesquisadores insatisfeitos com a abstração da epistemologia científica para dar conta da complexidade do cotidiano das organizações. Sua obra nos sensibiliza para a importância do relato, das narrativas do homem ordinário, dos processos de apropriação empreendidos pelos praticantes em busca de desvendar essa lógica de ação prática.

A obra de Certeau reforça a importância da perspectiva interpretativista para desvendar o cotidiano organizacional e contribui para superar a lógica instrumental como única matriz de compreensão da organização.

Dessa forma, este ensaio teórico tem a finalidade de, com sua base teórica, respaldar e estimular os estudos organizacionais que, a partir da teoria proposta por Certeau, recebem três importantes contribuições: primeiro, dando voz a organizações e indivíduos muitas vezes preteridos nos estudos do campo da administração, ampliando o alcance da ciência; segundo, criando um arcabouço para compreensão de fenômenos de mudança e agência das organizações; terceiro, contribuindo para a compreensão das rotinas que aparentemente se "repetem", mas que, como destaca Clot (2010) em uníssono com Certeau, "não há repetição na repetição". Há sempre invenção nessa realidade: uma invenção invisível para uma epistemologia "científica".

\section{Referências}

BISPO, M. D. S.; GODOY, A. S. A Etnometodologia enquanto caminho teórico metodológico para investigação da aprendizagem nas organizações. Revista de Administração Contemporânea, Maringá, v. 16, n. 5, p. 684-704, 2012.

BONDÍA, J. L. Notas sobre a experiência e o saber da experiência. Revista Brasileira de Educação, Rio de Janeiro, n. 19. p. 20-29. jan./fev./mar./abr. 2002. 
BOURDIEU, Pierre; PASSERON, Jean-Claude. Reproduction in education, society and culture. Sage, 1990.

BRUNER, J. Realidade mental, mundos possíveis. Porto Alegre: Artes Médicas, 1997.

BUEGER, C.; GADINGER, F. The play of international practices. International Studies Quarterly, [S. I.], v. 59, n. 3, p. 1-27, 2015.

BULGACOV, Yara L. M.; CHAVES, Carlos J. A.; VILELA, Juliana S.; VOGT, Sérgio S. A abordagem da prática proposta por Nicolini: base para uma "teoria" fundamentada. In: CONGRESSO BRASILEIRO DE ESTUDOS ORGANIZACIONAIS, 4., 2016, Porto Alegre. Anais [...]. Porto Alegre: [s.n.], 2016. p. 1-12.

CERTEAU, Michel de. A invenção do cotidiano: artes de fazer. 22. ed. Petrópolis: Vozes, 2014. v. 1.

CLOT, Y. Trabalho e poder de agir. Belo Horizonte: Fabrefacum, 2010.

CZARNIAWSKA, B. After practice: a personal reflection. Nordic Journal of Working Life Studies, [S. I.], v. 5, n. 3, p. 105, 2015.

DURAN, M. Uma leitura do cotidiano escolar com Michel de Certeau. International Studies on Law and Education, [S. I.], v. 12, p. 43-48, 2012.

FARIA, A. M.; LEITE-DA-SILVA, A. R. Estudos organizacionais baseados em Michel de Certeau: a produção internacional entre 2006 E 2015. Revista Alcance, Biguaçu, v. 24, n. 2, p. 209, 2017.

KÖHLER, J.; GEELS, F. W.; KERN, F.; et al. An agenda for sustainability transitions research: State of the art and future directions. Environmental Innovation and Societal Transitions, [S. I.], v. 31, p. 1-32, 2019. Disponível em: https://doi.org/10.1016/j.eist.2019.01.004. Acesso em: 27 mar. 2019.

MACHADO, Filipe C. L.; FERNANDES, Talita A.; SILVA, Alfredo R. L. da. Michel de Certeau e estudos organizacionais: uma leitura do cenário brasileiro. Caderno de Administração, Maringá, v. 25, n.2, p. 24-43, jul./dez. 2017.

MASCARENHAS, André O. Etnografia e cultura organizacional: uma contribuição da antropologia à administração de empresas. RAE - Revista de Administração de Empresas, São Paulo, v. 42, n. 2, abr./jun. 2002.

NICOLINI, D. Articulating practice through the interview to the double. Management Learning, [S. I.], v. 40, n. 2, p. 195-212, 2009.

NICOLINI, D. Practice theory, work, and organization: an introduction. Oxford: Oxford University Press, 2012.

NICOLINI, D.; MONTEIRO, P. The practice approach: for a praxeology of organisational and management studies. In: LANGLEY, Ann; TSOUKAS, Haridimos. The SAGE handbook of process organization studies, [S. I.]: SAGE Publications, 2016. p. 110-126. Link. Acesso em: 23 mar. 2019.

ORLIKOWSKI, W. J. Practice in research: phenomenon, perspective and philosophy. In: GLOSORKHI, D.; ROULEAU, L; SEIDL, D.; VAARA, E. (org.). Cambridge handbook of strategy as practice. Cambridge: Cambridge University Press, 2015. p. 70-83.

PASSERON, Jean-Claude. Morte de um amigo, fim de um pensador. In: ENCREVÉ, Pierre; LAGRAVE, Rose-Marie. Trabalhar com Bourdieu. Rio de Janeiro: Bertrand Brasil, 2005.

PEREIRA, M. H. de F.; SARTI, F. M. A leitura entre táticas e estratégias? consumo cultural e práticas epistolares. História da Educação, [S. I.], v. 14, n. 31, p. 195-217, 2010.

RECKWITZ, A. Toward a theory of social practices: A development in culturalist theorizing. European Journal of Social Theory, [S. I.], v. 5, n. 2, p. 243-263, 2002. Link. Acesso em: 23 mar. 2019.

SANDBERG, J.; TSOUKAS, H. Grasping the logic of practice: Theorizing through practical rationality. Academy of Management Review, [S. I.], v. 36, n. 2, p. 338-360, 2011. 
SANTOS, L. L. da S.; ALCADIPANI, R. Por uma epistemologia das práticas organizacionais: a contribuição de Theodore Schatzki. Organização e Sociedade, Salvador, v. 22, n. 72, p. 79-98, 2015

SCHATZKI, T. R.; CETINA, K. K.; SAVIGNY, E. Von. The practice turn in

contemporary theory. New York: Routledge, 2005.

SPINK, Peter K. Micro cadeias produtivas e a nanoeconomia: repensando o trabalho decente. Cadernos de Psicologia Social do Trabalho, São Paulo, v. 12, n. 2, p. 227-241, 2009.

SPINK, Peter K. O lugar do lugar na análise organizacional. RAC. Revista de Administração Contemporânea, Curitiba, v. 5, p. 11-34, 2001.

SPINK, Peter K. O pesquisador conversador no cotidiano. Psicologia \& Sociedade, Recife, v. 20, p. 70-77, 2008.

TSOUKAS, $\mathrm{H}$. The practice of theory: a knowledge-based view of the development in organization studies. In: TSOUKAS, H. Complex Knowledge: studies in organizational epistemology. Oxford: Oxford University Press, 2005. p. 427.

WENGER, E. Comunidades de práctica: aprendizaje, significado e identidad. Barcelona: Paidos, 2011.

\section{Contato:}

Rafael Carvalho Machado

E-mail: rafael.machado@gmail.com

Franciely Chropacz

E-mail: francielych@gmail.com

Yara Lucia Mazzioti Bulgacov

E-mail: ybulgacov@gmail.com 